Pensamiento Crítico Vol. 21 No 1, pp. 83 - 92

\title{
La teoría del ciclo monetario endógeno en la explicación de los ciclos económicos. Perú: 2002-2014
}

The theory of endogenous monetary cicle in the explanation of the economic cicles. Perú: 2002-2014

[Recepción: Marzo de 2016 / Conformidad: Mayo de 2016]

Pablo Rivas Santos ${ }^{1}$

\section{RESUMEN}

El presente artículo describe sistemáticamente de qué manera la explicación monetaria de los ciclos económicos aclara cómo influyó la política monetaria (en el corto, mediano y largo plazo) en los ciclos económicos. La materia de estudio de tal explicación es el auge de la producción y la inevitable subsiguiente recesión general.

La esencia de esta explicación es que el BCRP consideró elevada la tasa de interés de mercado, lo que indujo al BCRP a reducirla mediante una política monetaria expansiva (que mantiene baja la tasa de interés de referencia). Tal consideración le indujo a adoptar tal política monetaria que causó los ciclos económicos.

Palabras clave: Banco Central de Reserva, Producción, Tasas de interés de referencia, Ciclos económicos.

1 Profesor de Economía Monetaria e investigador del Instituto de Investigaciones Económicas de la Facultad de Ciencias Económicas de la Universidad Nacional Mayor de San Marcos. 


\title{
Pensamiento Crítico Vol. ᄅl No I
}

\begin{abstract}
This article systematically describes how monetary explanation of the business cycle explain show it influenced the monetary policy (in the short, medium and long term) economic cycles. The subject matter of suchan explanation is the ise of production and the subsequent global recession unavoidable.

The essence of this explanation is that the Central Bank considered high interest rate market prompting the Central Bank to reduce it by an expansionary monetary policy (which maittain slow interest rate reference). This consideration induced him to take such a monetary policy that caused economic cycles.
\end{abstract}

Keywords: Central Bank Reserves, Production, Benchmark interest rates, Economic cycles.

\section{Introducción}

Al comenzar tal política monetaria, proyectos de inversión que no eran rentables y que no se hubieran ejecutado (sí la tasa de interés no hubiera bajado) ahora son rentables y se ejecutan. Esta situación más activa en los negocios conduce a una creciente demanda de trabajo que causa una subida de los salarios. Esto aumenta el consumo de aquellos trabajadores cuyos salarios han subido a causa de esa mayor demanda de trabajadores desatada por empresarios que amplían su producción. De ese aumento de la demanda de bienes de consumo, los empresarios deducen que es rentable invertir y producir más.

Este auge derrocha (en inoportunas inversiones) las escasas existencias de capital, reduciendo (por un excesivo consumo de capital) las disponibilidades de este. Es decir, se inician proyectos de inversión de largo plazo al mismo tiempo que los capitales necesarios para que se completen esos proyectos se están consumiendo.

Esas inoportunas inversiones del auge inmovilizan capitales en determinados cometidos (capitales que fueron extraídos de otros cometidos donde atendían las más urgentes necesidades de los consumidores). Estos capitales están mal distribuidos entre los sectores productivos porque no es posible aprovechar la capacidad productiva de esos capitales al no disponerse de los factores de producción complementarios. 


\section{Pablo Rivas Santos}

A medida que el proceso de mercado guía esos proyectos de inversión de largo plazo hacia sus etapas finales: no todos esos proyectos van a ser completados rentablemente.

En vísperas de la recesión, el endeudamiento por necesidad permite que algunos empresarios completen sus proyectos y minimicen sus pérdidas.

En la fase recesiva, las altas tasas de interés impulsadas por esa demanda por necesidad provocan que la gente ahorre y reduzca su consumo. Los recursos así liberados constituyen un ahorro forzoso -compromiso de recursos relacionados con un auge que no cuadra con las preferencias intertemporales de los consumidores-. Con ese margen para sostener el auge (sobre la base del ahorro forzoso), la economía es forzada a crecer a una tasa más baja.

\section{El modelo}

El escenario de auge temporal surge como consecuencia de una política monetaria expansiva que mantiene baja la tasa de interés de referencia.

A partir de este escenario, se forman ciclos económicos porque la tasa de interés de referencia es menor que la tasa de interés de mercado.

Esta política monetaria distorsiona el funcionar del mercado de fondos prestables porque las familias obtienen una tasa de interés menor que su tasa de descuento temporal, lo que desincentiva el ahorro (e incentiva el consumo) y los empresarios (que financian sus proyectos de inversión de largo plazo con cargo a endeudamiento) pagan una tasa de interés menor por los préstamos que perciben, observándose un aumento de esos proyectos de inversión (aun cuando no dispongan de suficientes recursos para financiar esos proyectos de inversión). Por tanto, esa política monetaria genera un diferencial entre ahorro e inversión (ahorro menor que la inversión) que se cubre con inyección de dinero fiduciario.

Los empresarios reaccionan más ante esa política monetaria cuanto más se alejan del sector producción bienes de consumo, por el mayor impacto de esa política monetaria sobre el valor actual de sus proyectos de inversión de largo plazo. Por tanto, esa política monetaria desvía la estructura intertemporal del capital hacia el sector producción 


\section{Pensamiento Crítico Vol. ᄅl No I}

bienes duraderos, generando sobreinversiones de largo plazo que el mercado no podrá absorber.

El auge es temporal porque los empresarios (inducidos por la abundancia de crédito barato) desean invertir más en proyectos de inversión de largo plazo y las familias prefieren ahorrar menos, generando una pugna por los factores de producción escasos. Esta pugna (que se resuelve a favor de la demanda excesiva de inversión de largo plazo) aumentará la tasa de interés que encarecerá los costos financieros de las empresas. Así, esa sobreinversión de largo plazo dejará de ser rentable y un buen número de empresas padecerán dificultades financieras o incluso la quiebra. Como resultado, aumentará el desempleo, reduciéndose los ingresos de las familias y contrayéndose el consumo. La economía entrará a una fase recesiva, destinada a eliminar las malas inversiones realizadas durante esa política monetaria.

\section{Mecanismos de impulso y propagación de los ciclos económicos}

Para contrastar los mecanismos de impulso y propagación, se usan datos trimestrales de las brechas de la producción y la tasa de interés real.

Estas variables se miden en desviaciones cíclicas respecto de su tendencia de largo plazo (calculada mediante el filtro de Hodrick-Prescott) para asegurar su estacionariedad. Los resultados de las pruebas de raíces unitarias indican que esas variables son estacionarias al nivel de significancia de $5 \%$.

\section{Mecanismo de impulso}

a) Esa política monetaria causó, en el sentido de Granger, distorsiones en la estructura del proceso de producción.

Es decir, esa política monetaria, al distorsionar la estructura intertemporal de capital, distorsionó la estructura del proceso de producción.

b) La variación de esa política monetaria causó, en el sentido de Granger, variación en el PBI durante 2002-2014. 


\section{Pablo Rivas Santos}

\section{Mecanismo de propagación}

Un aumento de esa política monetaria determinó que ese auge sea temporal porque esa distorsión en la estructura del proceso de producción provocó que este auge se convierta en recesión a medida que el mercado descubrió las malas inversiones inducidas por esa política monetaria de abundancia de crédito barato.

Así, esa política monetaria expansiva, al distorsionar la estructura del proceso de producción y el comportamiento del $\mathrm{PBI}$, constata que existen puntos de inflexión endógenos y revela que existen ciclos económicos que se autoperpetúan.

Se formaliza este proceso mediante un modelo VAR de retardos distribuidos del PBIt como función de rezagos de esa política monetaria $\left(\mathrm{IREAL}_{\mathrm{t}-\mathrm{i}}\right)$

$$
\mathrm{PBI}_{\mathrm{t}}=\alpha+\sum_{i=0}^{n} \beta_{\mathrm{i}} \operatorname{IREAL}_{\mathrm{t}-\mathrm{i}}+\varepsilon_{\mathrm{i}}
$$

Un aumento de esa política monetaria causó periodos de auge $\sum_{i=0}^{p} \beta_{\mathrm{i}}>0$ seguido de periodos recesivos $\sum_{i=p+1}^{n} \beta_{i}<0$

c) La política monetaria expansiva se revierte cuando aparece la escasez de bienes de capital (causada por el auge).

Las primeras correlaciones positivas confirman que esa política monetaria expansiva generó un efecto liquidez estadísticamente significativo hasta el $4^{\circ}$ trimestre (aumentando esa política monetaria). Pero, a partir del $8^{\circ}$ trimestre, esas correlaciones se tornan negativas siendo estadísticamente significativo entre los trimestres $13^{\circ}$ y $15^{\circ}$. Así, esa política monetaria expansiva se revierte cuando aparece la escasez de bienes de capital causada por el auge.

Y esa intervención del BCRP para contrarrestar las presiones inflacionarias acentúa esa reversión de la política monetaria, reforzando las bases de la posterior recesión. 


\section{Pensamiento Crítico Vol. 己l NoI}

d) El aumento del ratio producción bienes duraderos/producción bienes de consumo (causado por el auge) se revierte endógenamente cuando el mercado descubre los malos procesos de inversión inducidos por la abundancia de crédito barato (burbuja financiera precedente).

Esa política monetaria iniciada en la fase recesiva causa esa abundancia de crédito barato que estimula la sobreinversión en proyectos de inversión de largo plazo, distorsionando la estructura intertemporal del capital de la economía.

El resultado es un escenario de auge temporal porque esa sobreinversion es asignativamente ineficiente pues no responde al volumen de bienes de capital de la economía.

En este escenario de auge temporal, gran parte de esos proyectos de inversión de largo plazo realizados en la etapa de economía de burbuja financiera dejan de ser rentables y deben liquidarse.

Es entonces cuando ese aumento del ratio producción bienes duraderos /producción bienes de consumo (causado por el auge) se revierte endógenamente, reduciéndose ese ratio en la fase recesiva del ciclo económico.

La relación política monetaria expansiva y ratio de la producción ilustra el comportamiento cíclico de la estructura intertemporal del capital de la economía, que a su vez sería reflejo de la propia persistencia del ciclo económico.

A partir de la relación política monetaria expansiva y comportamiento cíclico del PBI (relación que define las áreas de recesión, recuperación y auge y ralentización y recesión) en la fase de auge hay un auge del sector bienes duraderos en perjuicio del sector bienes de consumo, como consecuencia del efecto descuento temporal; y en la fase recesiva, hay una recesión del sector bienes duraderos (sector más intensivo en tiempo y capital) conforme el mercado descubre los errores de inversión inducidos por los procesos de esa política monetaria.

El efecto de aumentar esa política monetaria expansiva es negativo sobre el ratio de la producción en el $1^{\circ}$ y $2^{\circ}$ trimestre (lo que revela un uso anticíclico de esa política monetaria). Pero, este efecto negativo se desvanece entre el $3^{\circ}$ y $4^{\circ}$ trimestre llegando 


\section{Pablo Rivas Santos}

a ser positivo. Esta reversión de los $\beta_{\mathrm{i}}$ reflejaría el efecto de auge retardado (que a su vez resulta de la propia persistencia del ciclo económico que tendría ese aumento de la política monetaria sobre el sector bienes duraderos en relación con el sector bienes de consumo). No obstante, al final del auge este efecto positivo se desvanece, llegando a ser negativo en el inicio de la recesión.

Así, la política monetaria tuvo un efecto amplificado positivo sobre el sector materiales de construcción y bienes de consumo duradero en la fase de auge y un efecto amplificado negativo sobre ese sector de materiales de construcción y bienes de consumo duradero en la fase recesiva.

e) El auge del PBI se revierte cuando el mercado descubre los malos procesos de inversión inducidos por la abundancia de crédito barato.

La fase de auge del PBI estuvo precedida (con varios trimestres de antelación) por un aumento de esa política monetaria expansiva (convirtiéndose este aumento en un indicador adelantado del aumento de la producción). Así, este aumento estimuló el PBI con cierto retardo.

No obstante, con el transcurso del tiempo, este estímulo se desvaneció llegando a ser negativo cuando el mercado descubrió los malos procesos de inversión inducidos por la burbuja crediticia precedente.

El efecto de esa política monetaria expansiva (sobre el comportamiento cíclico del PBI) evidencia que existen puntos de inflexión endógenos.

La fase recesiva estuvo precedida (con varios trimestres de antelación) por un aumento de esta política monetaria con niveles altos de tasa de interés (convirtiéndose este aumento en un indicador adelantado de la caída de la producción).

Así, la economía transitó de un periodo de auge a un periodo de recesión que estimuló un nuevo uso expansivo de la política monetaria. 


\section{Pensamiento Crítico Vol. 己l NoI}

\section{Conclusiones}

La teoría del ciclo monetario endógeno trata de evitar los escenarios de burbuja financiera que preceden a los escenarios recesivos.

El sistema bancario de reserva fraccionaria (bajo la dirección del BCRP) crea burbujas financieras que conducen a la formación de ciclos económicos expansivo-recesivos que se autoperpetúan.

Cuando aumenta esa política monetaria, se acumulan las malas inversiones en el sector bienes duraderos, distorsionando la estructura productiva de la economía, que no responde ni a las disponibilidades de recursos reales de los productores ni a las preferencias de consumo intertemporal de los consumidores. Finalmente, la estructura productiva deberá reajustarse a estas disponibilidades y preferencia, a costa de un proceso recesivo mediante el cual se liquidarán esas malas inversiones a largo plazo (realizadas durante la etapa de burbuja financiera precedente) que el mercado no es capaz de absorber.

A partir de estos supuestos, se examinó el comportamiento cíclico del PBI entre 2002 y 2014, a la luz de las predicciones de la teoría del ciclo monetario endógeno.

Para ello se analizaron los mecanismos de impulso y propagación del ciclo monetario endógeno, recurriendo al contraste de causalidad de Granger y a un modelo VAR.

Usando la brecha tasa de interés real 2002-2014 (como una aproximación al control de la tasa de interés de referencia) se muestra que el grado de laxitud de la política monetaria incide en la estructura del proceso de producción y en el comportamiento cíclico del PBI. Un aumento de esa política monetaria tuvo un efecto diferencial positivo sobre la producción del sector bienes duraderos respecto al sector bienes de consumo. Ese efecto positivo diferencial se desvanece al final del auge, llegando a revertirse en el inicio de la recesión. Este resultado ilustra la existencia de ciclos expansivos-recesivos que se autoperpetúan en línea con las predicciones de la teoría del ciclo monetario endógeno. 


\section{Pablo Rivas Santos}

Usando un modelo VAR se constata que existe un uso anticíclico de la política monetaria que afecta con cierto retardo (entre $3^{\circ}$ y $4^{\circ}$ trimestres) al ratio de la producción que representa la estructura intertemporal del capital. Este efecto, con cierto retardo, también se observa sobre el comportamiento cíclico del PBI.

\section{Referencias bibliográficas}

Alonso Neira, Miguel A. (2005). Las Teorías del Ciclo en el Marco de la Literatura sobre los Ciclos Económicos. Argentina. Revista Libertas XII, Vol. 5, Año 5, № 15, 40-58.

Alonso Neira, Miguel A, Bagus Philipp, Rallo Julián, Juan Ramón (2011) Teorías del Ciclo Económico: Principales Contribuciones y Análisis a la Luz de las Aportaciones de la Escuela Austriaca de Economía. Argentina. Revista ICE, Vol. 3, Año 5, № 15, 40-58.

Alonso Neira, Miguel A, Bagus Philipp, Romero Ania, Alberto (2013). Una Ilustración Teórica de la Teoría Austriaca del Ciclo Económico: El Caso de Estados Unidos, 1988-2010. España. Revista Investigación Económica, Vol. LXXII, Año 7, № 20, 60-74.

Barro, Robert (1995). Macroeconomía. 3era edición. España. Alianza Editorial.

Friedman, Milton (1993). The Plucking Model of Business Fluctuations Revisited. Estados Unidos. Economic Inquiry, vol. 31, Año 19, № 17, 171-176.

Lucas, Robert (1987). Teoría de los Ciclos Económicos. 1era edición. Madrid. Alianza Editorial.

Von Hayek, Friedrich (1978). Desnacionalización del Dinero. 1era edición. Madrid. Editorial Continental.

Von Mises, Ludwig (1966). Teoría de la Moneda y el Crédito. 4ta edición. Madrid. Fundación Ignacio Villalonga. 


\section{Pensamiento Crítico Vol. 己l NoI}

Von Mises, Ludwig (1980). Acción Humana. 5ta edición España. Fundación Ignacio Villalonga.

Williamson, Stephen (2012). Macroeconomía. 1era edición. España. Editorial Pearson. 